\title{
Wa-Pa-Su project sustainability rating system: assessing sustainability in oil sands and heavy oil projects
}

\author{
C. A. Poveda \& M. G. Lipsett \\ Department of Mechanical Engineering, University of Alberta, Canada
}

\begin{abstract}
A number of environmental and sustainability rating systems have been developed and used around the world. This trend has been most notable in the building industry, where evolution of construction practices and concerns about environmental impact have led to the development of different environmental and sustainability assessment approaches, strategies, models, appraisals, and methodologies. The implementation of green technology and practices has brought economic, social, and environmental benefits with respect to improving sustainable development performance with an accompanying certification process. The framework for developing rating systems for building systems can be extended and applied in other industrial contexts. As global demand for energy continues to rise, unconventional petroleum extraction and production of petroleum substitutes are both becoming more necessary. Development and operation of unconventional oil projects can have considerable social, economic, and environmental impacts. For example, one the largest unconventional oil deposits in the world is the Athabasca oil sands in northern Canada. Government policy makers, industrial developers, and other stakeholders generally work together to develop oil sands projects in an environmentally responsible manner; however, the projects lack of an effective sustainable development measurement tool.
\end{abstract}

The WA-PA-SU project sustainability rating system is a proposed framework for measuring - in a consistent manner - the sustainability of development of unconventional petroleum projects in oil sands and heavy oil. The intent of the rating system is to have a tool that can be used by companies, stakeholders, and policy makers to measure and understand the range of impacts that projects may have over time. This assessment framework includes - but is not limited to - 
regulatory requirements, as well as approaches for measuring sustainability on social, economic, and environmental grounds. This paper presents a brief history of oil sands development, and the structure of the rating system. This structure comprises a description of the different areas included in the rating system, and the rationale for the first tool, which is intended to assist practitioners and stakeholders in general to measure sustainable development of the oil sands and heavy oil projects.

Keywords: sustainability assessment, rating systems, oil and gas, oil sands, sustainable development, energy consumption.

\section{Alberta's oil sands: a very brief history}

Unconventional petroleum production requires some process other than simply pressurizing the reservoir to produce the oil from the ground. Unconventional production is thus more technologically challenging, and often more energy intensive, than conventional production.

Oil sand is an unconsolidated soil, comprising bitumen, silica sand, clays, and water. Bitumen is a highly viscous type of petroleum, primarily made up of residuals with some asphaltenes, which does not flow naturally from a deposit. Amendments such as heating the deposit or adding a solvent allow the bitumen to flow. As well, some preliminary refining is required to make the petroleum suitable for use in refineries to produce transportation fuels [1], by reducing the molecular weight of the hydrocarbon molecules. This can be done by coking to remove carbon and the addition of hydrogen, where the hydrogen is derived from natural gas.

Bitumen production from oil sands is only possible by unconventional means. In some locations, oil sand deposits are found at the earth's surface, and amenable to surface mining; but generally the deposits are deep underground. Canada and Venezuela have the two largest deposits of oil sands; however, smaller deposits of bituminous sands can be found around the world. The first documented oil sands mining operation was set up in northeastern France in 1745, adding refining capacities in 1857.

The development of the Alberta's oil sands has been extensively documented [2-5]. Fur traders reported that Canadian First Nations peoples used bitumen to waterproof their birch bark canoes. Henry Kelsey, manager of the Hudson's Bay Company (HBC) at York Factory, saw the first sample of bitumen from the Athabasca region in 1719 [5].

In 1842, the Geological Survey of Canada was established to explore for coal and other minerals, but it was not until 1875 that there was a decision to investigate the Athabasca oil sands, with drilling beginning in 1894. Additionally, natural gas was discovered in different parts of Canada: New Brunswick in 1859, south-western Ontario in 1866, and 55 kilometres northwest of Medicine Hat in 1883. In 1922 the International Bitumen Company was formed and built a small plant near Bitumount, 80 kilometres north of Fort McMurray, to produce bitumen for roofing and road surfacing. A year later Edmonton adopted natural gas for heating, lighting and cooking. Minerals rights 
were transferred from the Canadian federal government to the provinces in 1930, and the Alberta Department of Land and Mines was established. In the 1950s, oil replaced coal as Canada's largest single source of energy. Pipelines transported natural gas to Vancouver, Winnipeg, Toronto, and Montreal. Alberta established air quality standards in 1961, which included limits for industrial emissions of hydrogen sulphide and sulphur dioxide. The first oil sands plant, Great Canadian Oil sands (now Suncor) opened a mining and refining operation near Fort McMurray Alberta. Syncrude followed in 1978 with a plant at a neighbouring lease. With these plants came working groups in geotechniques, cumulative environmental effects measurement (air, water, and terrestrial), and others, with membership by researchers, government officials, and industry representatives. Licences to operate prohibit discharging process-affected water into watercourses, and so mining operations maintain tailings impoundments and recycle much of the water. Even so, there is a net import of water for oil sands production.

Since the 1980s, each province has the exclusive right to make laws in relation to the development, conversation, and management of natural gas in the province. Natural gas price deregulation in Canada began in 1985. In 1997, the Kyoto Protocol treaty was negotiated and came into effect on February 16th, 2005. (In 2011, Canada did not commit to signing the new treaty.) In the late 1990s, the Oil Sands Generic Regime set rates and established the federal accelerated capital cost allowance for oil sands projects, encouraging development of new projects.

In the early 2000s, the Government of Alberta implemented the Energy Tax Refund, and from 2003 to 2009 implemented the Natural Gas Rebate Program, to protect Alberta consumers from high natural gas prices. In 2005, Alberta's Mineable Oil Sands Strategy (MOSS) was produced by a steering group that included representatives from environmental organizations, First Nations, industry and government. They released plans for consulting on policy principles in a draft-for-discussion document called "Mineable Oil sands Strategy and Fort McMurray Mineable Oil Sands Integrated Resources Management Plan” [4].

The development of the oil sands has become a priority for policy makers. In 2006 the Oil Sands Ministerial Strategy Committee developed a short term action plan to address the social, environmental and economic impacts of oil sands developments. The Oil Sands Consultations Multi-Stakeholder Committee (MSC) held information meetings throughout the province and allowed Albertans to raise their opinion on how the oils sands should be developed. In 2007, the Oil Sands Sustainable Development Secretariat was created to address the different issues related to the rapid growth of the oil sands in Alberta; and a 20 year plan was released in 2009: Responsible Actions: A Plan for Alberta's Oil Sands [6].

This pace of development has brought oil sands to the attention of the general public, and has led to criticism of the energy-intensity, water use, industrial footprint and reclamation rate, and other environmental impacts associated with this type of unconventional production. Projects associated with oil sands, such 
as the Northern Gateway and Keystone XL pipeline projects, have also received close public scrutiny, including social issues as well as environmental issues.

\title{
2 The case for sustainability
}

The demand for better integrated and more proactive decision processes signals the transition from environmental assessment to sustainability assessment. The success for sustainability relies on understanding the fundamentals of what sustainability is, or at least what the search of sustainability requires [7]. The Brundtland Commission, formally known as the World Commission on Environment and Development (WCED), defines sustainable development as

\begin{abstract}
"development that meets the needs of the present without compromising the ability of future generations to meet their own needs. It contains within it two key concepts: 1) the concept of 'needs', in particular the essential needs of the world's poor, to which overriding priority should be given; and 2) the idea of limitations imposed by the state of technology and social organization on the environment's ability to meet present and future needs" [8].
\end{abstract}

The fundamental relationship between human cultures and biospheres can be represented with concentric circles, or as overlapping regions of interest. This relationship has been represented in different ways, which depend on the viewpoint and the perception of importance. Figure 1 shows 'the egg of wellbeing' adopted by the World Conservation Union, in which the yolk of an egg represents people immersed in the white of ecosystems [9]. Another version immerses the circle of economy inside the circle of society, which is in turn inside the circle of ecology. These two versions are models of what is now considered the "old" sustainability. The "new" sustainability is commonly represented by three pillars or circles (also called the triple bottom line) that intersect - ecology, society and economy - suggesting interdependency and mutually support amongst the three principles.

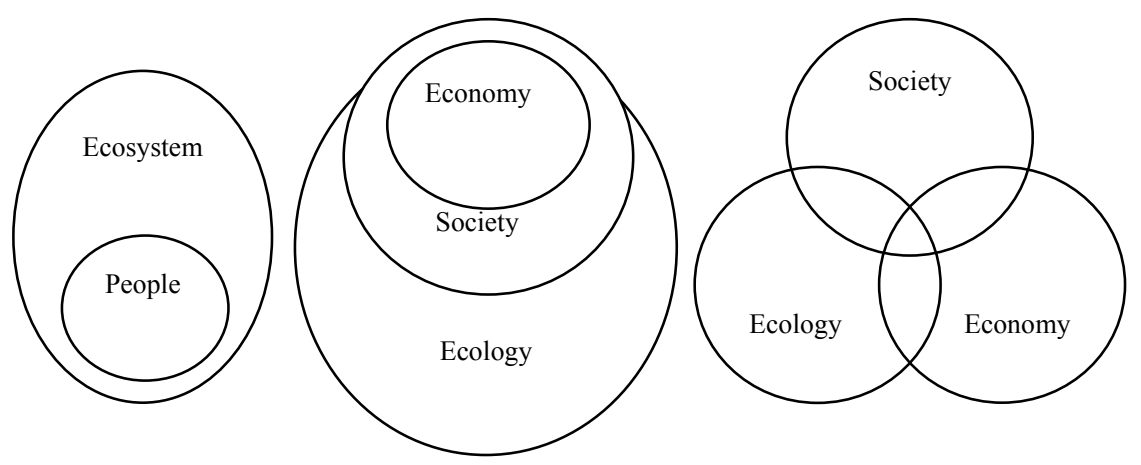

Figure 1: Graphical relationships amongst the principles of sustainability. 
Gibson et al. [7] describe the essentials of the concept. Sustainability is: 1) a challenge to conventional thinking and practice, 2) about long-term as well as short-term well-being, 3) comprehensive, covering all the core issues of decision making, 4) a recognition of links and interdependencies, especially between human and the biophysical foundation for life, 5) embedded in a world of complexity and surprise, in which precautionary approaches are necessary, 6) a recognition of both inviolable limits and endless opportunities for creative innovation, 7) about an open-ended process, not a state, 8) about intertwined means and ends (culture and governance as well as ecology, society and economy), and 9) both universal and context dependent. The essentials of sustainability carry a set of benefits - economical, societal, and environmental when applied to plan, programs, and policies of any organization.

The concept can be applied to any human endeavour. In the case of unconventional oil production, while the oil sands are a significant economic opportunity for Alberta and Canada, how this resource is exploited has substantial ramifications in different ways. These projects have economic, social, and environmental impact for present and future generations, and so sustainability essentials and principles must be considered.

Recognizing the importance of developing the oil sands in a sustainable manner, the government of Alberta released in 2009 the document "Responsible Action: A Plan for Alberta's Oil Sands, which outlines its approach for all levels of government, for industry, and for communities to address the economic, social and environmental challenges and opportunities in the oil sands regions" [1]. The document highlights six strategies: 1) develop Alberta's oil sands in an environmentally responsible way, 2) promote healthy communities and quality of life that attract and retains individuals, families, and business, 3) maximize long-term value for all Albertans through economic growth, stability, and resource optimization, 4) strengthen our proactive approach to Aboriginal consultation with a view to reconciling interests, 5) maximize research and innovation to further support sustainable development and unlock the deposit's potential, and 6) increase available information, develop measurement systems, and enhance accountability in the management of the oil sands.

Working with stakeholders facilitates to accomplish the goals of sustainability. Most believe that sustainability is guaranteed by imposing environmental regulations; however, other factors are to be considered (i.e. social, economic). Municipalities, Aboriginal communities, industry, researchers, and other public and private organizations are among the parties that impact or are impacted by the projects. Each of these stakeholder groups has particular interests and concerns when it comes to the oil sands projects and how to make new development more sustainable. Government sets standards and regulations, legal requirements that must be met by developing companies. But the strictest requirement is imposed by society, a social license that does not require a signature. Government, oil sands developing companies, and stakeholders are working together towards sustainable development, but one question remains: how is the sustainable development of oil sands projects being measured? 


\section{Sustainability assessments and sustainability-environmental rating systems as decision making tools}

Sustainability assessments and sustainable rating systems are tools to direct and support the planning and decision making process for projects toward accomplishing their sustainability goals. In the decision making process, a person, group, or organization attempts to make the best decision weighting the positives and negatives of each option available while considering all the alternatives, process that gets intricate based on the number of variables to be considered.

Sustainable rating systems have been designed to measure environmental performance of buildings. The term "building performance" is complex, since each stakeholder has particular interest and requirements [10]. Tenants are interested in comfort and health while economic performance is the interest of investor [11]. The building industry counts with a wide variety of sustainable ratings systems to choose from. ATHENA, BEAT 2002, BREEAM, LEED, Green Globes, CASBEE, Green Start are some of the existing sustainable rating systems. LEED, for example, addresses all building type and emphasizes initially in six categories: sustainable site, water efficiency, energy and atmosphere, materials and resources, indoor environmental quality, and innovation in design, adding the regional priority in its last version [12]. As LEED has been a success in North America and LEED certified projects are in more than 100 countries, BREEAM has demonstrated its applicability in Europe, developed in the United Kingdom by the Building Research Establishment (BRE). BRE has more than 100.000 buildings certified and operates in dozens of countries. BREEAM uses nine categories: management, health and wellbeing, energy, transport, water, materials, waste, land use and ecology, and pollution. These categories facilitate practitioners to make effective and efficient decisions in the use and operation of the resources involve the development of projects. As in other industries, oil sands and heavy oil projects must include in their evaluation economic, social, and environmental factors.

Gibson et al. [7] explain that sustainability includes the core issues of decision making. Sustainability is not one item in a list of considerations, but rather a framework and a set of relevant values integrated to comply with those considerations. The term is still often used narrowly to describe specific areas (e.g. environmental sustainability). Environmental Impact Assessment (EIA) and Strategic Environmental Assessment (SEA) are the foundation for sustainable assessment. While EIAs are more appropriate to project assessment, SEA applies to policies, plans and programmes. It is valid to differentiate between external and internal sustainability. External sustainability assessment is performed by regulatory bodies. Internal sustainability assessment is performed by planning and project proponents as part of the process of developing a proposal. External and internal sustainability assessment are both important if a shift towards more sustainable decision making takes place [13]. 
Sustainable rating systems support the decision making process throughout the project life cycle, or for certain phases of a project. In common practice, the designer does not have much interaction with the constructor; however, accomplishing the sustainability goals requires an integrated effort between the parties involved, regardless of the project delivery method used (e.g. design-bidbuild, design-build, integrated project delivery, etc.). This integrated approach assists the decision making process and minimizes design and building errors, among other benefits.

While a variety of sustainability assessment tools are available for practitioners, a sustainable rating system to measure the overall environmental performance in a consistent manner of oil sands and heavy oil projects has yet to be developed. Critical decisions are made in all projects to accomplish the goals of sustainable development; consequently, structured methods and approaches to design should be considered for project development based on sustainability principles [14].

\section{Are environmental regulations enough?}

Regulations can take different forms: legal, social, self-regulation, co-regulation, and market regulation. For the exploration, construction, operation and maintenance of oil sands and heavy oil projects, a series of approvals, licenses, dispositions, permits and registrations are required. Alberta Environment, the Energy Resources Conservation Board (ERCB) and Alberta Sustainable Resource Development are part of the provincial agencies, and Environmental Canada, the Department of Oceans and Fisheries and Transport Canada operates at the federal level $[15,16]$.

Regulations include quantifiable measures that allow companies to meet (and demonstrate meeting) the requirements imposed by government authorities. Mechanisms include regulations, approvals, licenses, permits, and registrations. These documented processes and measures have a crucial role throughout a project life cycle; however, a question remains: are regulations enough to demonstrate environmental and sustainable development performance? Meeting the requirements of regulations does not imply that the projects have an overall successful performance from a sustainability standpoint. In the case of the oil sands and heavy oil projects, operating companies meet regulatory requirements of different agencies; and these companies cannot demonstrate convincingly that current and future projects can deliver sustainable development objectives.

Table 1 shows some of the main differences between regulations and a sustainable rating system. The main objective of a sustainable rating system is to assist constructors, regulatory agencies, developers, stakeholders, and others in decision making processes related to improving the sustainability of industrial development. 
Table 1: Differences between regulations and sustainable rating systems.

\begin{tabular}{|l|l|}
\hline \multicolumn{1}{|c|}{ Regulations } & \multicolumn{1}{c|}{ Sustainable Rating Systems } \\
\hline Compulsory & Non-Compulsory \\
\hline Limited decision making support & $\begin{array}{l}\text { Decision making support } \\
\text { throughout project life cycle. }\end{array}$ \\
\hline Reactive Approach & Pro-Active Approach \\
\hline $\begin{array}{l}\text { Primarily environmental and legal } \\
\text { factors are regulated. Other sustainable } \\
\text { criteria are not included (e.g. social } \\
\text { economic, etc.) }\end{array}$ & $\begin{array}{l}\text { Sustainable principles included in } \\
\text { addition to environmental and legal } \\
\text { factors (e.g. management, research, } \\
\text { community, etc.). }\end{array}$ \\
\hline $\begin{array}{l}\text { Selected criteria are measured. } \\
\text { Operational Stage }\end{array}$ \\
\hline $\begin{array}{l}\text { Accomplishment measure by specific } \\
\text { criteria. }\end{array}$ & $\begin{array}{l}\text { Large variety of criteria measured: } \\
\text { (regulated and non-regulated) }\end{array}$ \\
\hline $\begin{array}{l}\text { Flexible criteria with some mandatory } \\
\text { factors. }\end{array}$ & $\begin{array}{l}\text { Users decide which criteria to meet } \\
\text { to obtain the desired score, but } \\
\text { criteria based on regulated factors } \\
\text { must be met. }\end{array}$ \\
\hline
\end{tabular}

\section{Introducing the sustainable rating system and its potential benefits}

Following the trends of environmental and sustainable development performance measurements it is appropriate to consider the development of a sustainable rating system for industrial projects with application to oil sands and heavy oil projects. The rating system combines the structure of oil sands and heavy oil projects, the concepts of sustainable rating systems (including the fundamentals of sustainable development, methods for multi-criteria decision making, and management best practices), and legal requirements (e.g. regulations) as part of the credit weighting tool.

The name of the rating system has several contexts. Wa-Pa-Su was the name of a Cree native who brought the first sample of bitumen from the largest oil deposit in Canada to Henry Kelsey, manager of the Hudson's Bay Company (HBC) at York Factory in 1719 [5]. In the Cree language, Wa-Pa-Su translates as white swan. The acronym stands for world and people align for sustainability.

The development of a sustainable rating system for oil sands and heavy oil projects responds to the need for dialogue and understanding amongst stakeholders on the triple impact of technological options in unconventional oil 
development. The system can contribute to a variety of areas, including sustainable development, research, environmental science, finance and economy, social, productivity, construction, management (e.g. risk management, performance evaluation, decision making, etc), design, health, public relations, and employee retention. The design and implementation of a sustainable rating impacts developers, constructors, stakeholders and society in general, because practices are modified to meet the requirements of the tool.

Sustainable rating systems carry a number of benefits when they have been implemented [17]. Existing sustainable rating systems have demonstrated that their implementation delivers economic and social benefits while reduces the impact on the environment.

Some benefits that the $\mathrm{Wa}-\mathrm{Pa}-\mathrm{Su}$ project sustainability rating system may deliver include, but not limited to, the following: 1) provide a tool to implement green and sustainable performance excellence during difference phases of the project life cycle, 2) help organizations to assess their performance in meeting environmental, social and economic objectives, 3) provide productive positive publicity, 4) assist in expressing civic leadership, 5) facilitate improved morale and engagement of employees and stakeholders, 6) support strong local economies, 7) facilitate market transformation, 8) reduce environmental impact due to project construction and operations, 9) stimulate reduced energy intensity through improved process efficiency, 10) support the decision making process throughout the project life cycle, 11) allow companies to show leadership in new business practices in the oil and gas industry, and 12) demonstrate that companies can make innovative continuous improvements to the triple bottom line [18].

\section{Wa-Pa-Su project sustainability rating system structure (sub-divisions, areas of excellence and criteria)}

A main differentiation is made between the considerations taken in the structure design of the rating system and the areas included in the integrated approach to measure sustainability mentioned in section 5. The structure design of the Wa$\mathrm{Pa}-\mathrm{Su}$ project sustainability rating system complies with two basic requirements: the oil sands and heavy oil projects structure and the principles and goals of sustainable development.

The structure of the life cycle of a large industrial project assists in the selection of the rating system sub-divisions; and the objectives of sustainable development support the selection of the different areas of excellence and criteria. Furthermore, criteria selection considers the measurements of the three different pillars of sustainability: economic, social, and environmental.

Based on preliminary feedback from practitioners and researchers, the structure design of the $\mathrm{Wa}-\mathrm{Pa}-\mathrm{u}$ project sustainability rating system considers three fundamental characteristics: applicability, functionality, and user friendliness. Since the $\mathrm{Wa}-\mathrm{Pa}-\mathrm{Su}$ project sustainability rating system intents to be incorporated into a well-structured, mostly regulated and fast paced industry, 
stakeholders rely on tools that can be implemented easily within current management practices, without compromising sustainability principles.

Figure 2 illustrates the typical oil sand project life cycle. Oil sands and heavy oil projects are large and complex. Many different groups are part of each phase of a project. The factor of manageability of criteria and diversity of stakeholders influences the sub-division identification. The different sub-divisions considered in the Wa-Pa-Su project sustianbility rating system are: 1) project integration, 2) provisional housing/buildings, 3) permanent housing/buildings, 4) roads, 5) oil transportation and storage, 6) mining process, 7) in-situ process, 8) upgrading and refining, 9) shutdown and reclamation, and 10) co-products and waste streams capture and storage [19]. As not all oil sands project contain each subdivision, the structure of the rating system allows to break it into different "pieces" which can be used modularly to calculate the project sustainability overall score. This feature reinforces the practical functionality of the rating system. Additionally, the integrated sustainability assessment approach, currently in development, supports and aligns with this systems approach.

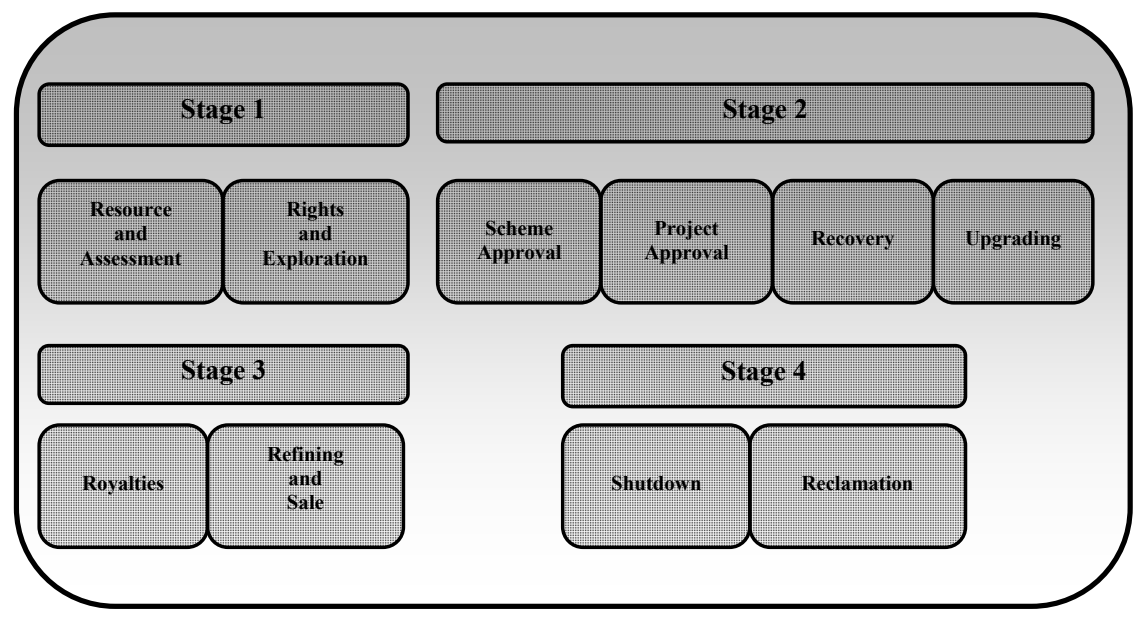

Figure 2: $\quad$ Oil sands project life cycle [10].

Three different aspects contribute to the selection of the different areas of excellence: resources involved in the projects development, expectations of stakeholders, and potential environmental, economic and social impacts [18]. Ten areas of excellence were identified: project and environmental management excellence (PEME); site and soil resource excellence (SSRE); water resource excellence (WRE); atmosphere and air resource excellence (AARE); natural and artificial lighting excellence (NALE); energy resource excellence (ERE); resources and materials excellence (RME); innovation in design and operations excellence (IDOE); infrastructure and buildings excellence (IBE); and education, research and community excellence (ERCE). The word excellence is added with the aim of reminding the rating system users of the ultimate goal of the tool, the stakeholder objectives, and the purpose of striving for sustainable development. 
Every sub-division in the rating is integrated by the ten areas of excellence. Table 2 presents a sample of this integration: the mining processes sub-division with its respective areas of excellence.

Table 2: Sample of Integration between sub-divisions and areas of excellence.

\begin{tabular}{|l|}
\hline \multicolumn{1}{|c|}{ 6. Mining Process } \\
\hline Project and Environmental Management Excellence - PEME \\
\hline Site and Soil Resource Excellence - SSRE \\
\hline Water Resource Excellence - WRE \\
\hline Atmosphere and Air Resource Excellence - AARE \\
\hline Natural and Artificial Lighting Excellence - NALE \\
\hline Energy Resource Excellence - ERE \\
\hline Resources and Materials Excellence - RME \\
\hline Innovation in Design and Operations Excellence - IDOE \\
\hline Infrastructure and Buildings Excellence - IBE \\
\hline Education, Research and Community Excellence - ERCE \\
\hline
\end{tabular}

Finally, each area of excellence combines a series of unique and specific criteria. The criteria are selected considering the three principles of sustainability, moreover with the continuous thought of minimizing social, economic and environmental impacts created by the development of the projects. Criteria use acronyms to differentiate between each other; for example, IDOEP\&D6xx refers to certain criteria $(\mathrm{xx})$ that belong to sub-division six (6[mining process]) for the innovation in design and operation excellence area (IDOE) during the planning and design (P\&D) phase [19].

\section{Conclusions and future work}

Sustainable assessment tools and sustainable rating systems assist practitioners, researchers, project stakeholders, and decision makers to accomplish the goals of sustainability in each of its three pillars: social, economic and environmental. The results of the assessment process must facilitate the implementation of the requirements to meet sustainability objectives. Gibson et al. [7] explains: "ideally, every undertaking that emerges from an assessment process would help meet every one of the requirements for sustainability. Every new project, programme, policy and plan would assist in the building of socio-ecosystem integrity, provide good jobs and other opportunities for a decent life, reduce inequities, cut overall energy and material use, strengthen democratic practice, 
foster habitual respect for people and nature avoid risks and prepare for adaptation. These are the qualities we need for sustainability."

Since the oil sands and heavy oil projects continue with a rapid pace of development, it is essential for the parties involved in the exploration, construction and operation of the projects (e.g. developing companies, stakeholders, government, subcontractors, etc.) to find a tool to measure environmental and sustainable development performance in a consistent manner. In most industries, measuring environmental and sustainability performance is relevant for continual improvement practices; but, in the oil and gas industry, the appropriate assessment tool must support the decision making process, because of to the diversity of groups involved in the development of the projects. Including the right stakeholders is key to an effective assessment process. On the other hand, a weak stakeholder identification process compromises the fundamental objective of sustainability, which is finding the right balance among the social, environmental and economic pillars.

Decision makers often find themselves in difficult and potentially compromising situations when choices are to be made among trade-offs. Deciding whether social and economic benefits prevail instead of potential environmental impacts usually leads to conflicts and compromise amount the different parties involved in the project. The concept of sustainability implies finding the balance of social, economics, and environmental needs; however, two main characteristics must be highlighted: development of the right process to find the balance, and definition of "needs".

This structured analysis of the underlying form of a heavy industrial project, linked to sustainability goals, is a framework for an integrated understanding of how technology selection and operation can mesh with societal values. Future work includes decision criteria selection, quantitative measures for monitoring criteria (especially for key sustainability metrics), assessing different methods for engagement of diverse stakeholders (for communication as well as decisionmaking), and decision methods based on a combination of qualitative and quantitative criteria.

\section{References}

[1] Oil Sands 101. Alberta Energy. Oil Sands 101, www.energy.alberta.ca/OilSands/1723.asp

[2] Breen, D., Alberta's Petroleum Industry and The Conservation Board, The University of Alberta Press: Edmonton, 1993.

[3] Chastko, P.A., Developing Alberta's Oil Sands: From Karl Clark to Kyoto, University of Calgary Press: Calgary, 2004.

[4] Energy's History in Alberta. Alberta Energy,www.energy.alberta.ca/ About_Us/1133.asp

[5] Kelly, G., The Oil Sands - Canada's Path to Clean Energy?, Kingsley Publishing Service Inc: Cochrane, 2009.

[6] Responsible Actions: A Plan for Alberta's Oil Sands. Government of Alberta, www.treasuryboard.alberta.ca/ResponsibleActions.cfm 
[7] Gibson, R. B., Hassan, S., Holtz, S., Tansey, J., and Whitelaw, G. (2005)., Sustainability assessment: criteria and processes, Earthscan Publications Ltd: London, 2005.

[8] United Nations General Assembly. Report of the World Commission on Environment and Development. General Assembly Resolution 42/187, 11 December 1987, www.un-documents.net/k-001303.htm

[9] Guijt, I., Moiseev, A., and Prescott-Allen, R. IUNC Resource Kit for Sustainability Assessment. Geneva: IUCN Monitoring and Evaluation Initiative, 2001.

[10] Cole, RJ. Emerging trends in building environmental assessment methods. Building Research \& Information, 26 (1), pp. 3-16, 1998.

[11] Haapio, A., and Viitaniemi, P. A critical review of building environmental assessment tools. Environmental Impact Assessment Review, 28, pp. 469482, 2008.

[12] U. S. Green Building Council. LEED - Leadership in Energy and Environmental Design: Green Building Rating Systems, Version 1.0, US Green Building Council, 2009.

[13] Post, N. M. Gurus seek a building rating system with even greener pastures. Engineering News-Records, 258(8), pp. 22, 2007.

[14] Poveda, C.A. and Lipsett, M. G., A Review of Sustainability Assessment and Sustainability/Environmental Rating Systems and Credit Weighting Tools. Journal of Sustainable Development, 4(6), pp. 36-55, 2011.

[15] Regulations. Oil Sands Developers Group,www.oilsandsdevelopers.ca/index.php/thank-you/ oil-sands-facts/regulations/

[16] Rules and Regulators. Oil Sands Developers Group, www.oilsandsdevelopers.ca/index.php/thank-you/oil-sandsfacts/environment/rules-regulators/

[17] Yudelson, J., The Green Building Revolution, Island Press: Washington D.C, 2008.

[18] Poveda, C.A. and Lipsett, M. G., A Rating System for Sustainability of Industrial Projects with Application in Oil Sands and Heavy Oil Projects: Origins and Fundamentals. Journal of Sustainable Development, 4(3), pp. 59-71, 2011.

[19] Poveda, C.A. and Lipsett, M. G., A Rating System for Sustainability of Industrial Projects with Application in Oil Sands and Heavy Oil Projects: Areas of Excellence, Sub-Divisions, and Management Interaction. Journal of Sustainable Development, 4(4), pp. 3-13, 2011. 